Research Article

\title{
Prevalence of hypertension in an area of urban Varanasi, India and its association with selected demographic factors
}

\author{
Madhu Priya*, C. P. Mishra
}

Department of Community Medicine, Institute of Medical Sciences, Banaras Hindu University, Varanasi, India

Received: 20 April 2016

Accepted: 14 May 2016

*Correspondence:
Dr. Madhu Priya,
E-mail: mdhpry03@yahoo.co.in

Copyright: (C) the author(s), publisher and licensee Medip Academy. This is an open-access article distributed under the terms of the Creative Commons Attribution Non-Commercial License, which permits unrestricted non-commercial use, distribution, and reproduction in any medium, provided the original work is properly cited.

\begin{abstract}
Background: Non communicable diseases (NCDs) are the leading cause of death in WHO South East Asian Region and the rising trend is attributed to a variety of factors viz smoking, sedentary life style etc. Hypertension is considered as the principle risk factor for heart attack and stroke. The main objective was to assess the prevalence and spectrum of hypertension and its association with selected demographic factors in an area of urban Varanasi.

Methods: This cross- sectional community based study was undertaken in a selected area of urban Varanasi. The study sample comprised of subjects 25 years and above. After obtaining ethical clearance and taking consent from study subjects, they were specifically interviewed for selected demographic characteristics using pre designed and pre tested proforma. Their blood pressure was measured using electronic BP machine following standard technique. The data was entered in personal computer and analyzed with SPSS.

Results: Out of 611 subjects, $314(51.4 \%)$ subjects were male and 297 (48.6\%) were female. 51.7\% and $20.0 \%$ subjects were categorized as normal and pre hypertensive respectively. As much as $19.6 \%$ and $8.7 \%$ subjects were in stage 1 and stage 2 hypertension. Presence of hypertension increased significantly ( $<<0.001$ ) with advancing age.

Conclusions: Hypertension is a significant problem in study subjects. Nearly one fifth of the subjects were in pre hypertensive stage. Preventive strategies should be directed to them for positive impact.
\end{abstract}

Keywords: Demographic factors, Hypertension, Pre hypertension, Spectrum

\section{INTRODUCTION}

Hypertension, also known as high or raised blood pressure, is a global public health issue. It contributes to the burden of heart disease, stroke and kidney failure and premature mortality and disability. It disproportionately affects populations in low and middle-income countries where health systems are weak. Hypertension rarely causes symptoms in the early stages and many people go undiagnosed. Those who are diagnosed may not have access to treatment and may not be able to successfully control their illness over the long term. ${ }^{1}$ Globally cardiovascular disease accounts for approximately 17 million deaths a year, nearly one third of the total deaths. Of these, complications of hypertension account for 9.4 million deaths worldwide every year. ${ }^{2}$ Hypertension is responsible for at least $45 \%$ of deaths due to heart disease (total ischemic heart disease), and $51 \%$ of deaths due to stroke. In 2008, worldwide, approximately $40 \%$ of adults aged 25 years and above had been diagnosed with hypertension; the number of people with the condition rose from 600 million in 1980 to 1 billion in $2008 .^{3}$

The prevalence of hypertension is highest in the African Region at $46 \%$ of adults aged 25 and above, while the lowest prevalence at $35 \%$ is found in the Americas. Overall, high-income countries have a lower prevalence of hypertension (35\%) than other groups at $40 \%$. Chronic non-communicable diseases (NCDs), particularly cardiovascular diseases (CVD) and its principal risk 
factor high blood pressure is increasing in the South East Asia Region (SEAR). In 2008, of the 7.9 million NCD related deaths in SEAR, 3.6 million were attributable to CVD alone. This is projected to increase to 12.5 million by 2030 . Notably, unlike in developed countries, most of the deaths occur at younger ages with consequent adverse health, economic and social implications. ${ }^{1}$

The increasing prevalence of hypertension is attributed to population growth, ageing and behavioural risk factors, such as unhealthy diet, harmful use of alcohol, lack of physical activity, excess weight and exposure to persistent stress. The adverse health consequences of hypertension are compounded because many people affected also have other health risk factors that increase the odds of heart attack, stroke and kidney failure. These risk factors include tobacco use, obesity, high cholesterol and diabetes mellitus. Industrialization, socio-economic development, urbanization, changing age structure, changing lifestyles have placed India at a position where it is facing a growing burden of NCDs.

In India, NCDs accounted for $40 \%$ of all hospital stays and $35 \%$ of all outpatient visits in $2004 .^{4}$ Also, chronic diseases are estimated to account for $53 \%$ of all deaths and $44 \%$ of disability-adjusted life-years (DALYs) lost in 2005 . $^{5}$ As of 2005 , India experienced the "highest loss in potentially productive years of life" worldwide. ${ }^{6}$ Hypertension exerts a substantial public health burden on cardiovascular health status and healthcare systems in India., ${ }^{6,7}$

Hypertension is directly responsible for $57 \%$ of all stroke deaths and $24 \%$ of all coronary heart disease (CHD) deaths in India. In an analysis of worldwide data for the global burden of hypertension, $20.6 \%$ of Indian men and $20.9 \%$ of Indian women were hypertensive in 2005 . The rates for hypertension in percentage are projected to go up to 22.9 and 23.6 for Indian men and women, respectively by 2025.8

Rapid unplanned urbanization also tends to promote the development of hypertension as a result of unhealthy environments that encourage consumption of fast food, sedentary behaviour, tobacco use and the harmful use of alcohol. Epidemiological evidence reveals that population demographic changes in India have increased risk factors of hypertension.

There is increasing life expectancy, urbanization, development and affluence in India. ${ }^{9}$ In 1901, only $11 \%$ of the population was living in an urban area; this proportion was $17.6 \%$ in $1951,18.3 \%$ in $1961,20.2 \%$ in $1971,23.7 \%$ in 1981 and $26.1 \%$ in 1991 . There is a strong correlation between urbanization and increase in hypertension prevalence.

An alarming rise in hypertension projected by Global Burden of Hypertension 2005 study, the GBD 2010 study and non-communicable disease India specific data portray a grim picture for the $17.8 \%$ of the world's population who reside in India. ${ }^{2,8}$ With this background this study was undertaken in an urban area of Varanasi.

The specific objectives of the study were; (a) to assess the prevalence and spectrum of hypertension and (b) to find out its association with selected demographic factors in an area of urban Varanasi, India.

\section{METHODS}

This community based cross sectional study was carried out in Sunderpur, which is urban field practice area of Department of Community Medicine, Institute of Medical Sciences, Banaras Hindu University. The consent of participants was obtained before the start of the study.

It is a community based cross sectional study. Individuals of age of 25 years and above constituted subjects of the study. The required sample size was computed based on the assumption that prevalence of hypertension in adults aged 25 years and above was $40 \%$ as per WHO $2008^{3}$ using the formula $\mathrm{N}=\mathrm{Z} \times \mathrm{P} \times \mathrm{Q} / \mathrm{L}^{2}$ where $\mathrm{P}=$ Prevalence $\mathrm{Q}=1-\mathrm{P}$ and $\mathrm{Z}=$ constant $=\alpha^{2}=(1.96)^{2}$.

Taking permissible level of error as $10 \%$ the computed sample size came out to be 576. However, keeping allowance for non-response a total of 611 subjects $(\geq 25$ years) were considered for the study. For their selection, two sectors were selected by lottery method from the five sectors of Sunderpur. In the selected sectors subjects $\geq 25$ years of age were selected by total enumeration. A pre designed and pre tested proforma and an electronic blood pressure monitor served as tools for this study.

\section{Techniques of study}

In order to assess the prevalence of hypertension total enumeration of the study subjects ( $\geq 25$ years of age) was done by interviewing head or any responsible member of the family. Age recording of the study subjects was done by life events using staircase approach. Besides age and sex, information pertaining to religion, caste, type of family were also noted on the proforma.

Systolic blood pressure (SBP) and diastolic blood pressure (DBP) of each study subject was recorded adopting criteria as given below.

- Blood pressure was measured by an electronic blood pressure monitor with a cuff of proper size to encircle $80 \%$ of the arm circumference.

- The blood pressure was taken in the right arm with the subject relaxed and comfortable.

- The blood pressure reading was taken after ensuring a gap of 30 minutes in the event of smoking or coffee ingestion and after the subjects had emptied their bladder. 
- Subjects were seated with their back supported and with their legs resting on the ground and in uncrossed position for 5 minutes.

- Two readings were taken 2 minutes apart and averages of two readings were recorded.

Based on JNC-7 criteria subjects were categorized into normal (SBP $<120$ and $\mathrm{DBP}<80 \mathrm{~mm}$ of $\mathrm{Hg}$ ), Prehypertensive $(\mathrm{SBP}=120-139$ and $\mathrm{DBP}=80-89 \mathrm{~mm}$ of $\mathrm{Hg})$, Hypertension stage $1 \quad(\mathrm{SBP}=140-159$ and $\mathrm{DBP}=90-99$ $\mathrm{mm}$ of $\mathrm{Hg}$ ) and Hypertension stage 2 (SBP $\geq 160$ and $\mathrm{DBP} \geq 100 \mathrm{~mm}$ of $\mathrm{Hg}){ }^{9}$ As per JNC-7 criteria, subjects in stage 1 and stage 2 hypertension are considered as hypertensive.

\section{Analysis of data}

Data thus generated was analyzed with the help of Microsoft excel 2007 and SPSS version $16^{\text {th }}$ software. Appropriate tables were generated and statistics were applied for statistical association and inference. Chisquare test was used for testing statistical significance and $\mathrm{p}<0.05$ was considered as significant.

\section{RESULTS}

Out of 611 subjects $\geq 25$ years, $48.4 \%$ subjects belonged to the age group $25-39$ years; $51.4 \%$ subjects were male and $48.6 \%$ were female. Majority $(99.5 \%)$ of them were Hindu. As much as $39.6 \%, 40.6 \%$ and $19.8 \%$ subjects belonged to SC/ST, OBC and other caste category, respectively. Three hundred ninety three (64.3\%) subjects were from joint family; remaining $35.7 \%$ subjects were from nuclear family. In case of $53.2 \%$ subjects, family size was $\leq 6$ whereas $17.0 \%$ subjects have family size was greater than or equal to 10 (Table 1).

Table 1: General characteristics of study subjects $(\mathrm{N}=611)$.

\begin{tabular}{|lccc|}
\hline \multirow{4}{*}{ Variables (in years) } & & No. & $\%$ \\
\cline { 2 - 4 } & $25-39$ & 296 & 48.4 \\
\cline { 2 - 4 } & $40-49$ & 117 & 19.1 \\
\cline { 2 - 4 } & $50-59$ & 118 & 19.3 \\
\hline \multirow{3}{*}{ Sex } & $\geq 60$ & 80 & 13.1 \\
\hline \multirow{3}{*}{ Religion } & Male & 314 & 51.4 \\
\hline \multirow{3}{*}{ Caste } & Female & 297 & 48.6 \\
\hline Type of & Hindu & 608 & 99.5 \\
\hline family & Others & 02 & 0.3 \\
\hline \multirow{3}{*}{ Family size } & SC/ST & 242 & 0.2 \\
\cline { 2 - 4 } & OBC & 248 & 49.6 \\
\hline & Others & 121 & 19.6 \\
\hline & Joint & 393 & 64.3 \\
\hline & Nuclear & 218 & 35.7 \\
\hline
\end{tabular}

\section{$\square$ Normal $\square$ Pre-Hypertension $\square$ Stage-1 $\square$ Stage-2}

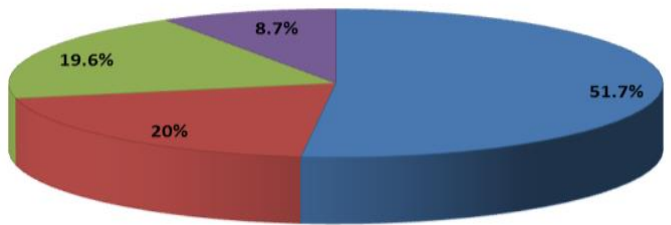

Figure 1: Distribution of study subjects according to their blood pressure category.

Out of 611 subjects, $51.7 \%$ and $20.0 \%$ subjects were categorized as normal and pre hypertensive, respectively. As much as $19.6 \%$ and $8.7 \%$ subjects were in stage 1 and stage 2 hypertension (Figure 1). Presence of hypertension increased significantly $(\mathrm{p}<0.001)$ with advancing age. This was $7.8 \%$ in $25-39,23.9 \%$ in $40-49,54.2 \%$ in $50-59$ and $72.5 \%$ in more than or equal to 60 year age group, respectively. As much as $51.3 \%$ males and $52.2 \%$ female subjects were normotensive. Out of 314 male subjects $27.7 \%$ subjects were hypertensive; male subjects with stage 1 and stage 2 hypertension were $18.5 \%$ and $9.2 \%$, respectively. Of 297 female subjects, $20.9 \%$ and $8.1 \%$ subjects were in stage 1 and stage 2 hypertension, respectively. In all $29.0 \%$ female subjects were hypertensive (Table 2).

Of 608 Hindu subjects, $315(51.8 \%)$ subjects were normotensive. $173(28.5 \%)$ Hindu subjects were hypertensive; subjects in stage 1 and stage 2 were $19.7 \%$ and $8.7 \%$, respectively. There existed no significant difference $(p>0.05)$ in religion wise prevalence of hypertension in study subjects (Table 2).

Sixty one (25.25\%) SC/ST subjects were hypertensive; subjects with stage 1 and stage 2 hypertension were $17.4 \%$ and $7.9 \%$, respectively.

As much as $18.5 \%$ and $9.3 \%$ OBC subjects were in stage 1 and stage 2 hypertension; in all $27.8 \%$ subjects were hypertensive. One third of the subjects belonging to other caste category were hypertensive; subjects in stage 1 and stage 2 hypertension were $26.4 \%$ and $9.1 \%$, respectively. There existed no significant difference $(p>0.05)$ in the occurrence of hypertension in subjects in different caste categories (Table 2).

Out of 393 subjects belonging to joint family, 31.04\% subjects were hypertensive; subjects in stage 1 and stage 2 hypertension were $22.6 \%$ and $8.4 \%$ respectively. Out of 218 subjects from nuclear family, $23.4 \%$ subjects were hypertensive; subjects in stage 1 and stage 2 hypertension were $14.2 \%$ and $9.2 \%$, respectively. There existed no significant difference $(\mathrm{p}>0.05)$ between types of family of 
study subjects and blood pressure categories (Table 2). Out of 325 subjects having family size $\leq 6,84(25.8 \%)$ subjects were hypertensive; subjects from this category with stage 1 an stage 2 hypertension were $18.5 \%$ and $7.4 \%$ respectively. As much as $30.8 \%$ and $31.7 \%$ subjects having family size 7-9 and $\geq 10$ were hypertensive. There existed no significant difference ( $p>0.05$ ) between family size and blood pressure categories of study subjects (Table 2).

Table 2: Distribution of study subjects according to their demographic profile and blood pressure category.

\begin{tabular}{|c|c|c|c|c|c|c|c|c|c|c|}
\hline \multirow{3}{*}{ Characteristic } & \multirow{3}{*}{ No. } & \multicolumn{8}{|c|}{ Blood Pressure Category } & \multirow{3}{*}{$\begin{array}{l}\text { Test of } \\
\text { significance }\end{array}$} \\
\hline & & \multicolumn{2}{|c|}{ Normal } & \multicolumn{2}{|c|}{ Pre-hypertension } & \multicolumn{2}{|c|}{ Stage- 1} & \multicolumn{2}{|c|}{ Stage- 2} & \\
\hline & & No. & $\%$ & No. & $\%$ & No. & $\%$ & No. & $\%$ & \\
\hline \multicolumn{11}{|l|}{ Age (in years) } \\
\hline $25-39$ & 296 & 214 & 72.3 & 59 & 19.9 & 22 & 07.4 & 01 & 0.3 & \multirow{4}{*}{$\begin{array}{l}\chi^{2}=271.5 \mathrm{df}=9 \\
P<0.05\end{array}$} \\
\hline $40-49$ & 117 & 64 & 54.7 & 25 & 21.4 & 23 & 19.7 & 05 & 4.3 & \\
\hline $50-59$ & 118 & 33 & 28.0 & 21 & 17.8 & 52 & 44.1 & 12 & 10.2 & \\
\hline$\geq 60$ & 80 & 05 & 6.2 & 17 & 21.2 & 23 & 28.8 & 35 & 43.8 & \\
\hline \multicolumn{11}{|l|}{ Sex } \\
\hline Male & 314 & 161 & 51.3 & 66 & 21.0 & 58 & 18.5 & 29 & 9.2 & \multirow{2}{*}{$\begin{array}{l}\chi^{2}=1.066 \mathrm{df}=1 \\
P=0.785\end{array}$} \\
\hline Female & 297 & 155 & 52.2 & 56 & 18.9 & 62 & 20.9 & 24 & 8.1 & \\
\hline \multicolumn{11}{|l|}{ Religion } \\
\hline Hindu & 608 & 315 & 51.8 & 120 & 19.7 & 120 & 19.7 & 53 & 8.7 & \multirow{3}{*}{$\begin{array}{l}\chi^{2}=5.500 \\
\mathrm{df}=6 \\
P=0.481\end{array}$} \\
\hline Muslim & 02 & 01 & 50.0 & 01 & 50.0 & 0 & 0.0 & 0 & 0.0 & \\
\hline Others & 01 & 00 & 0.0 & 01 & 100.0 & 0 & 0.0 & 0 & 0.0 & \\
\hline \multicolumn{11}{|l|}{ Caste } \\
\hline $\mathrm{SC} / \mathrm{ST}$ & 242 & 122 & 50.4 & 59 & 24.4 & 42 & 17.4 & 19 & 7.9 & \multirow{3}{*}{$\begin{array}{l}\chi^{2}=9.493 \mathrm{df}=6 \\
P=0.148\end{array}$} \\
\hline OBC & 248 & 138 & 55.6 & 41 & 16.5 & 46 & 18.5 & 23 & 9.3 & \\
\hline Others & 121 & 56 & 46.3 & 22 & 18.2 & 32 & 26.4 & 11 & 9.1 & \\
\hline \multicolumn{11}{|l|}{ Type of Family } \\
\hline Joint & 393 & 197 & 50.1 & 74 & 18.8 & 89 & 22.6 & 33 & 8.4 & \multirow{2}{*}{$\begin{array}{l}\chi^{2}=6.420 \mathrm{df}=3 \\
\mathrm{P}=0.093\end{array}$} \\
\hline Nuclear & 218 & 119 & 54.6 & 48 & 22.0 & 31 & 14.2 & 20 & 9.2 & \\
\hline \multicolumn{11}{|c|}{ Total No. of Family Members } \\
\hline$\leq 6$ & 325 & 174 & 53.5 & 67 & 20.6 & 60 & 18.5 & 24 & 7.4 & \multirow{3}{*}{$\begin{array}{l}\chi^{2}=8.058 \quad \mathrm{df}=6 \\
P=0.234\end{array}$} \\
\hline $7-9$ & 182 & 94 & 51.6 & 32 & 17.6 & 42 & 23.1 & 14 & 7.7 & \\
\hline$\geq 10$ & 104 & 48 & 46.2 & 23 & 22.1 & 18 & 17.3 & 15 & 14.4 & \\
\hline
\end{tabular}

\section{DISCUSSION}

Chronic diseases are on rise in India; these diseases are contributing significantly to productivity loss and contribute significantly for attributable burden of disease and load on health system. ${ }^{2,6,7,11,12}$ Several studies and non-communicable diseases country profile, 2011 highlights alarming situation due to hypertension., ${ }^{2,8,13,14}$

Using JNC VII classification- half of the subjects were normotensive. $^{10}$ Nearly 3 out of 10 subjects were hypertensive; two third of them were in stage 1 hypertension. Similar findings have been reported by several workers. ${ }^{15-17}$ Contrary to this several workers reported a higher prevalence of hypertension. ${ }^{17-23}$ Lower prevalence of hypertension has been observed by some researchers. ${ }^{24-27}$ The result of the present study shows an increase in prevalence of hypertension with an increase in age. This is in conformity with several Indian studies. $^{24,26,28,29}$ Varying pattern of hypertension with socio-economic status has been reported in several studies. $^{26,30,31}$

According to a study women had a lower prevalence of isolated diastolic blood pressure compared to men across all age groups. ${ }^{32}$ Rate of age associated increase in blood pressure accelerates in women around fifth and sixth decade of life and eventually exceeds that of men. However, results remain controversial. In the present observation there has been no difference in the magnitude of hypertension in male and female subjects. It is alarming to note that one fifth of the study subjects were in the stage of pre hypertension. Although they were free from the disease as per JNC-7 criteria, they were at potential risk of the disease. Spectrum of hypertension has been similar in males and females. There existed no significant difference in sex wise prevalence of hypertension in the study subjects. 
Urbanization is considered an important risk factor and determinant of hypertension. This disparity in the prevalence of hypertension in urban and rural areas can be attributed to the fact that different cut-off age and sample size for screening the population have been used. Different studies have also used different criteria for defining hypertension.

Although there has been no significant difference in religion wise prevalence of hypertension in study subjects. Much significance cannot be attached to the findings as there has been gross under representation of Muslim subjects. Caste has been used as a proxy indicator of socioeconomic status and it is expected that extent of hypertension may vary in different caste categories. However, in the present study, in Hindu subjects, caste was not significantly associated with the occurrence of hypertension. In the present study, type of family and family size have not exerted significant influence on the prevalence of disease.

Normal levels of both systolic and diastolic blood pressure are particularly important for the efficient functioning of vital organs such as the heart, brain and kidneys and for overall health and wellbeing. Hypertension is a significant problem in study subjects. Nearly one fifth of the subjects were in pre hypertensive stage.

According to JNC- 7 criteria they are free from disease but are at high risk of developing hypertension in near future. Although hypertension guidelines (2014) also known as JNC 8 is available, it has not changed classification of hypertension, but thresholds for pharmacologic treatment were defined. ${ }^{33}$

This is a serious warning signal and significant lifestyle interventions and dietary modifications are urgently needed. People need to know why raised blood pressure is dangerous, and how to take steps to control it. There are significant health and economic gains attached to early detection, adequate treatment and good control of hypertension.

Preventive strategies should be directed to them for positive impact. World Health Organization (WHO) has also emphasized the fact that addressing behavioural risk factors, e.g. unhealthy diet, harmful use of alcohol and physical inactivity, can prevent hypertension. Health promoting lifestyle modifications are recommended for individuals with pre-hypertension and as an adjunct to drug therapy in hypertensive individuals

\section{CONCLUSION}

Hypertension is a significant problem in study subjects and calls for concerted efforts from all stakeholders. Nearly one fifth of the subjects were in pre hypertensive stage. Preventive strategies should be directed to them for positive impact.
Funding: No funding sources

Conflict of interest: None declared

Ethical approval: The study was approved by the Institutional Ethics Committee of Banaras Hindu University, India

\section{REFERENCES}

1. World Health Organization. Review of salt and Health: Situation in South-East Asia Region, 2013.

2. Lim SS, Vos T, Flaxman AD, Danaei G, Kenji Shibuya K, Adair-Rohani H, AlMazroa MA, et al. A comparative risk assessment of burden of disease and injury attributable to 67 risk factors and risk factor clusters in 21 regions, 1990-2010 : a systematic analysis for the Global Burden of Disease Study 2010. Lancet. 2012;380(9859):222460.

3. World Health Organization. Causes of death 2008: data sources and methods. Geneva: WHO, 2011.

4. Mahal A, Karan A, Engelgau M. The Economic Implications of Non-Communicable Disease for India. Washington DC: The International Bank for Reconstruction and Development/The World Bank; 2009.

5. ICMR-MRC Workshop. Building Indo-Uk colloboration in chronic diseases. 2009. p. 16.

6. Reddy KS, Shah B, Varghese C, Ramadoss A. Responding to the threat of chronic diseases in India. The Lancet. 2005;366:1746-51.

7. Leeder S, Raymond S, Greenberg H, Liu H. A race against time. The challenge of cardiovascular disease in developing economies. New York:Columbia University; 2004.

8. Kearney PM, Whelton M, Reynolds K, Muntner P, Whelton PK, He J. Global burden of hypertension: analysis of worldwide data. Lancet. 2005;365:21723.

9. Gupta R. Meta-analysis of prevalence of hypertension in India. Indian Heart J. 1997;49:450.

10. The Seventh Report of The Joint National Committee On Prevention, Detection, Evaluation, And Treatment Of High Blood Pressure (JNC 7) U.S. Department of Health and Human Services, National Institute of Health; National Heart Lung and Blood Institute.NIH Publication No.03-5233, May 2003: 2-3.

11. Taylor DW. The Burden of Non-Communicable Diseases in India. Hamilton ON: The Cameron Institute; 2010. p. 13.

12. World Health Organization, Chronic Disease Report, 2005

13. Devi P, Rao M, Sigamani A, Faruqui A, Jose M, Gupta R, et al. Prevalence, risk factors and awareness of hypertension in India: a systematic review. J Hum Hypertens. 2013;27:281-7.

14. Non communicable diseases country profiles 2011. http://www.who.int/nmh/countries/ind_en.pdf [Accessed 10 May 2013]. 
15. Anchala R, Kannuri NK, Pant H, Khan H, Franco $\mathrm{OH}$, Di Angelantonio E, Prabhakaran D. Hypertension in India: a systematic review and meta-analysis of prevalence, awareness, and control of hypertension. J Hypertens. 2014 Jun;32(6):11707.

16. Gupta R, Gupta S, Gupta P, Prakash H. Prevalence and determinants of hypertension in the urban population of Jaipur in Western India. J Hypertens. 1995;13:1193-1200.4-13.

17. Ganguli D, Das N, Saha I, Chaudhuri D, Ghosh S, Dey S. Risk factors for hypertension in a population-based sample of postmenopausal women in Kolkata, West Bengal, India. Asia Pac J Public Health. 2013;5:388-97.

18. Gupta R. Prevalence of coronary heart disease and risk factors in an urban Indian population: Jaipur Heart Watch-2. Indian Heart J. 2002;54:59-66.

19. Gupta MM, Patil RK, Khan MI, Gupta SK. (2012). Effect of lifestyle risk factors on prevalence of hypertension in a defined urban population of Rewa. Natl J Comm Med. 2012;3(4):570-5.

20. Joshi SR, Saboo B, Vadivale M, Dani SI, Mithal A, Kaul U, et al. SITE Investigators Prevalence of diagnosed and undiagnosed diabetes and hypertension in India: results from the Screening India's Twin Epidemic (SITE) study. Diabetes Technol Ther. 2012;14:8-15.

21. Joseph A, Kutty VR, Soman CR. High risk for coronary heart disease in Thiruvanantpuram city: a study of serum lipids and other risk factors. India Heart J. 2000;51:29-35.

22. Maroof KA, Parashar P, Bansal R, Anand S. A study on hypertension among the bank employees of Meerut district of Uttar Pradesh. Indian Journal of Public Health. 2007;51(4):225-7.

23. Midha T, Idris MZ, Saran RK, Srivastav AK, Singh SK; Prevalence and determinants of hypertension in the urban and rural population of a north Indian district; East Afr J Public Health. 2009;6(3):268-73.

24. Anand MP. Prevalence and grades of hypertension amongst executives of Mumbai. J Assoc Phys Ind. 2000;48(12):1200-1.

25. Deepa R, Santirani CS, Pradeepa R, Mohan V. Is the rule of halves in hypertension still valis?
Evidence from the Chennai urban population study. J Assoc Pys India. 2003;51:153-7.

26. Malhotra P, Kumari S, Kumar R, Jain S, Sharma BK. Prevalence and determinants of hypertension in an un-industrialized rural population of north India. J Hum Hypertens. 1999;13(7):467-72.

27. Mohan V, Deepa R, Rani SS, Premlatha G. Prevalence of CAD and relationship to lipids in a selected population in South India. J Am Coll. Cardiol. 2001;38:682-7.

28. Shantirani CS, Pradeepa R, Deepa R, Premlata G, Saroja R, Mohan V. Prevalence and risk factors of hypertension in a selected South Indian PopulationThe Chennai Urban Population Study. J Assoc. Physicians India. 2003;51:20-7.

29. Chadha SL, Radhakrishnan S. Ramachandran K, Kaul U and Gopinath N. Prevalence, awareness and treatment of hypertension in urban population of Delhi. Ind J Ned.Res. 1990;92:233-40.

30. Hussain SA, Nayak KC, Gupta A. A study of prevalence of hypertension with reference to economic, educational, environmental and hereditary factors in general population of NorthWest Rajasthan. Ind Heart Jr. 1988;40(3);148-51.

31. Jajoo UN, Kalantri SP, Gupta OP, Jain AP, Gupta $\mathrm{K}$. The prevalence of hypertension in rural population around Sewagram. J Assoc Phys Ind. 1993;41(7):422-4.

32. Mohan V, Deepa M, Farooq S, Datta M, Deepa R. (2007) Prevalence, awareness and control of hypertension in Chennai - the Chennai Urban Rural Epidemiology Study (CURES - 52) Journal of the Association of Physicians of India. 2007;55:326-32.

33. James PA, Oparil S, Carter BL, Cushman WC, Dennison-Himmelfarb C, Handler J, et al. Evidence-based guideline for the management of high blood pressure in adults report from the panel members appointed to the eighth joint national committee (JNC 8). JAMA. 2014;311(5):507-20.

Cite this article as: Priya M, Mishra CP. Prevalence of hypertension in an area of urban Varanasi, India and its association with selected demographic factors. Int J Community Med Public Health 2016;3:1600-5. 